\title{
Indicators of landscape diversity derived from remote sensing based land cover maps - spatial and thematic aspects
}

\author{
Dariusz Ziolkowski, Konrad Turlej, Zbigniew Bochenek
}

Institute of Geodesy and Cartography

Modzelewskiego 27, 02-679 Warsaw, Poland

e-mail: dariusz.ziolkowski@igik.edu.pl

\begin{abstract}
Landscape is heterogeneous part of the Earth surface, forming mosaic of various habitats organized at different scales and levels (Johnson et al. 1992). The landscape pattern has important impact on ecological processes; hence its analysis through quantitative measures is essential for environmental studies. There are many indicators characterizing spatial structure of landscape at different level of detail; they enable analysis of landscape fragmentation at patch level, through studies at habitat level up to complex analyses at landscape level. Seven indicators, which are related to various levels of detail, were selected at the presented work. The following indicators have been studied: Patch Density, Edge Density, Patch Richness, Simpson Diversity Index, Natural Patch Richness, Percentage of Natural Landscape, Mean Natural Patch Area (McGarigal \& Marks 1995). First two indicators were used for analysis of landscape fragmentation at patch level, next two at land cover level, while the last three were applied for studies of natural and semi-natural classes at both levels. The studies were performed at six test areas located in different regions of Europe (France, Germany, Poland, Latvia, Spain and Italy), using two different land cover maps. First map was based on Very High Resolution (VHR) Kompsat satellite images ( $4 \mathrm{~m}$ spatial resolution); it included 8 land cover categories with 0.25 ha Minimum Mapping Unit (MMU). CORINE Land Cover (CLC) map 2006 (25 ha MMU) was the second map used for analyses. Number of land cover classes in case of CLC map varied from 9 for Poland till 14 for France. All above mentioned indicators were calculated for grids with 100, 200, 500 and 1000 meter cell size, corresponding to 1, 4, 25 and 100 ha, respectively. The obtained results reveal high usefulness of land cover maps based on VHR satellite images for analysis of landscape fragmentation, even for grids with $100 \mathrm{~m}$ cell size. It was found that at patch level these materials are superior to CLC classifications, irrespective of cell area. In case of land cover level VHR data are better while using 100 and $200 \mathrm{~m}$ grid cells, whereas for larger cell sizes - 500 and $1000 \mathrm{~m}$ - results are not so evident, depending on degree of landscape fragmentation and spatial structure characteristic for individual land cover classes.
\end{abstract}

Key words: landscape indicators, land cover classifications, landscape fragmentation

\section{Introduction}

Landscape is a very complex element of Earth surface; it is composed of various habitats arranged at different spatial structures. These structures influence ecological processes and the conditions of life for living organisms (Johnson et al. 1992). Changes in spatial structure of landscape caused by man's activity can make disturbances in ecological processes, leading to the loss of landscape integrity and biodiversity (Gardner et al. 1993; With 1999). Therefore, analysis of spatial structure of landscape with the use of various quantitative indicators is very important issue for ecological community, being used for analysis of ecological processes. There are many publications, which describe quantitative indicators characterizing structure of landscape at different levels of detail (e.g., O'Neill et al. 1988; Turner 1990; Turner \& Gardner 1991; Baker \& Cai 1992; McGarigal \& Marks 1995). They enable analysis of landscape fragmentation at patch level, at land cover, habitat or species level, up to complex analysis of the whole landscape. 
There are two basic factors influencing indicator's values, which characterize spatial structure of landscape: type and quality of input data (e.g. land cover map) and size of cell in which indicator is calculated. For the first factor spatial and thematic resolution is the most important. Spatial resolution is crucial in case of landscape fragmentation at patch level and using small grid cells, although it is important also in the other cases, as it was found in our study. Thematic resolution (number of land cover classes) becomes important in case of analyses at land cover level or at the whole landscape level.

Size of grid cell should be dependent on scale of the map (local, regional) and on level of the analyzed spatial structure of landscape (patches, habitats, whole landscape). It frequently results from spatial resolution of input data. Previous studies show dependencies between values of landscape metrics, resolution of input data and size of the grid cell (Wu 2002; Uuemaa et al. 2005)

The third factor which should be taken into account is the spatial range of the analyzed area. It should be adjusted to the degree of landscape differentiation, spatial resolution of input land cover maps and level of landscape analysis (patches, land cover or habitat classes, whole landscape). While in the case of landscape fragmentation, the studies are possible even on relatively small area, for habitat or whole landscape studies the extent of analysis should be larger.

Two land cover maps based on different input data were selected: maps derived from VHR Kompsat images (SATChMo classification) and from SPOT images (CORINE Land Cover 2006 classification). They are characterized by different spatial resolution and thematic content. The technical capabilities of CORINE Land Cover classification for obtaining of landscape metrics were considered in previous studies for various landscapes (Gimona et al. 2009; Gulinck et al 2001). For many ecological applications the results for CLC classification were also compared to the other data characterized by finer spatial resolution (Schmit et al 2006; Tormos et al 2011). In this study for analysis of landscape fragmentation seven indicators were selected, which describe landscape at various levels (patches, land cover classes, natural areas) and at four sizes of grid cell (100, 200, 500 and $1000 \mathrm{~m})$. The aim of the analyses was to assess usefulness of these two types of input data for fragmentation and structure studies at different levels and resolutions. The study was an extension of the works conducted by the Institute of Geodesy and Cartography and Space Research Centre within Geoland 2 SATChMo project. Land cover maps generated on the basis of Kompsat images were produced within this project (Lewinski et al. 2010, 2011). The first studies of usefulness of the materials for landscape structure analyses based on classifications from two test areas were conducted (Smith et al. 2012). At the presented study the scope of analysis was extended to four new test areas. Also the number of indicators increased from 4 to 7 , with division into 3 levels of details, as well as the same calculations were done using CORINE Land Cover maps (CLC). For Kompsat based classifications all indicators were determined for two dates (2009 and 2010) and maps of changes were generated. The main aim of the presented work is to make comparative analysis of usefulness of both classifications for studies of landscape structure at various levels of detail (patches, land cover classes, natural areas). All presented indicators were calculated at the Institute of Geodesy and Cartography using tools within eCognition environment and models within ERDAS IMAGINE environment.

\section{Study Area}

The works have been conducted on six test areas located in the following regions of Europe: southwestern France, northwestern Poland, southwestern Germany, western Italy (Sardinia), western Latvia and southwestern Spain. Each test site has the area ca. $120 \mathrm{~km}^{2}$, resulting from the size of Kompsat scene. Due to the test site location they have different characteristics related to land cover classes and their pattern, which has direct impact on landscape fragmentation. Location of particular test sites is presented in Figure 1.

Differentiation of test sites caused by landscape fragmentation is much better visible while using maps derived from VHR images due to much higher spatial resolution of Kompsat data (4 m), whereas thematic content is wider in case of CORINE Land Cover maps. In case of Kompsat based classifications (SATChMo) number of land cover classes is stable (8 classes, with the exception of Germany - lack of grasslands and other vegetation and Italy - lack of other vegetation). In case of CORINE classifications it varies from 9 (Poland) to 14 (France). In total, on all test sites 24 CORINE land cover classes appear: 4 classes of built-up areas, 8 classes of agricultural land, 10 natural and semi-natural classes, including 2 wetlands and 2 water categories. Only 3 CORINE classes occur on all 6 test sites $(112,211,242)$, whereas 8 classes appear solely on one test area. Exemplary land cover maps derived from Kompsat and CORINE Land Cover for French test site are presented in Figure 2. List of CORINE land cover classes for particular test sites is given in Table 1 .

Test site located in southwestern France is the most heterogeneous, taking into account both number of polygons and number of CLC classes. The lowest number of CLC classes (9) appears on test site located in Poland. This area is also characterized by the highest landscape homogeneity. Large crop fields prevail within this area, as well as compact forest complexes, although small patches of natural and semi-natural vegetation also appear. They are 


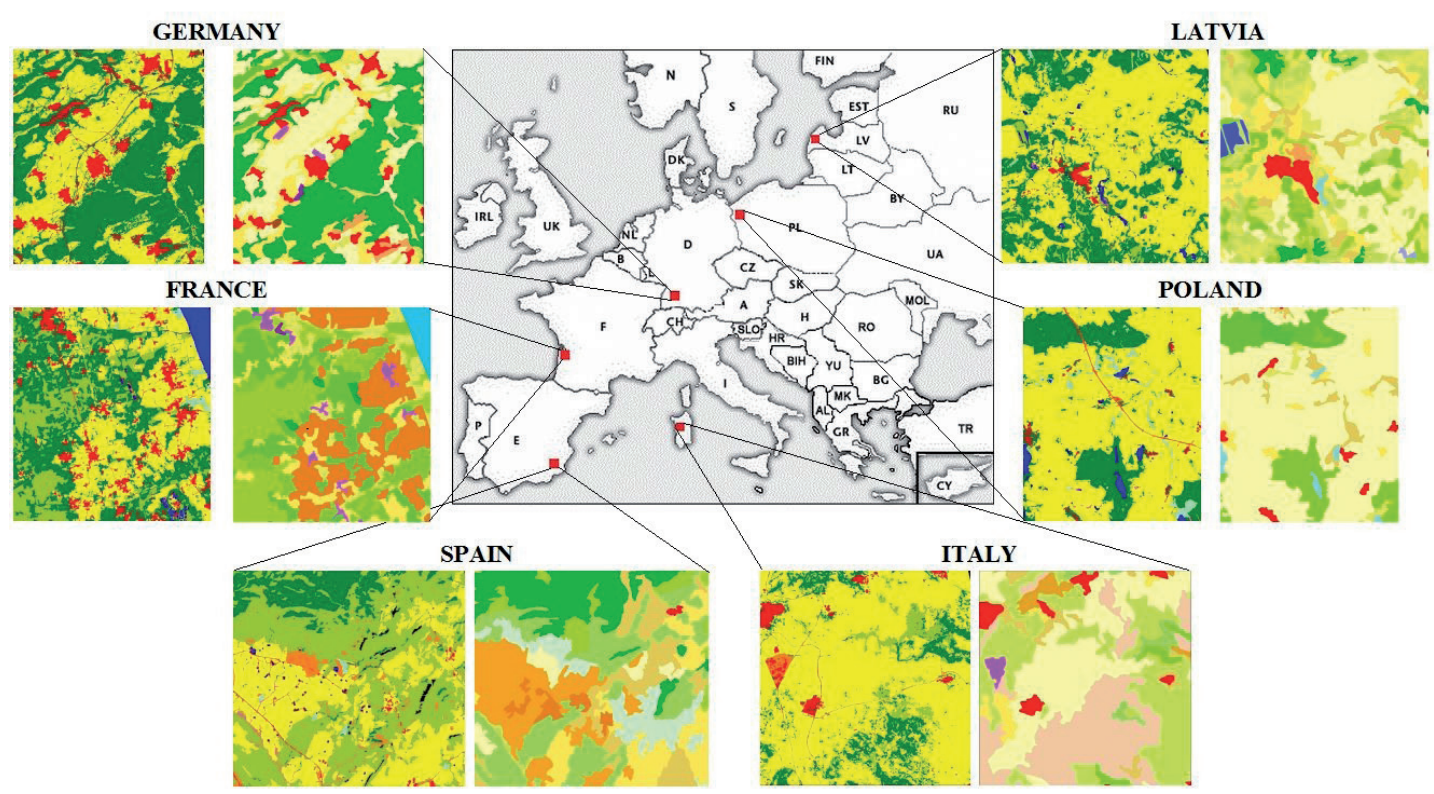

Figure 1. Location of test sites (red squares on the map of Europe). For each test site land cover maps were presented (Kompsat based - left, CORINE based - right). Legends for these maps are included in Figure 2 and Table 1

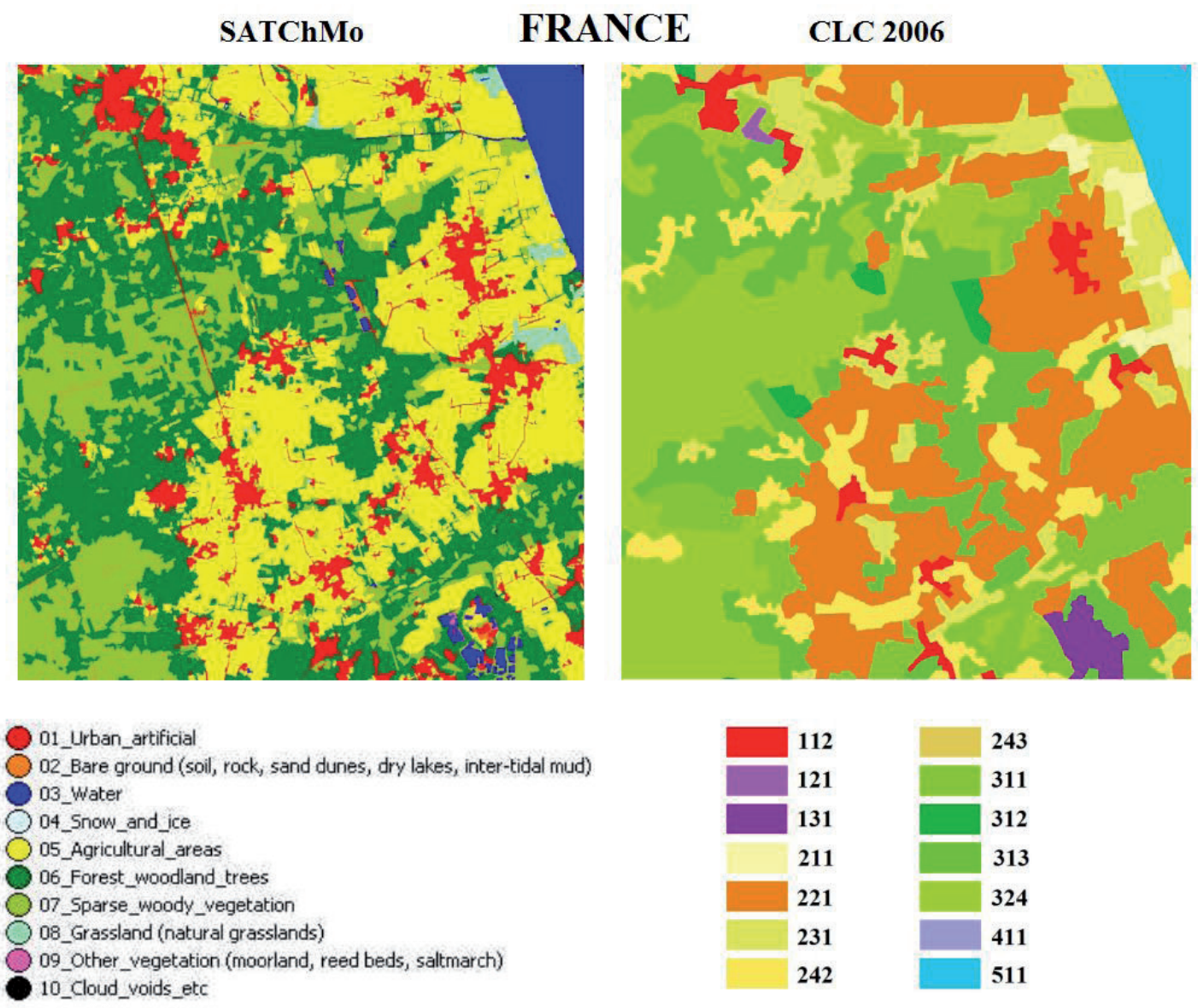

Figure 2. Test site in southwestern France. Land cover map generated from Kompsat image using SATChMo legend is presented to the left; land cover map prepared according to CORINE Land Cover legend is presented to the right 
Table 1. List of CORINE Land Cover classes appearing on all six test sites

\begin{tabular}{|c|c|c|c|c|c|}
\hline Lp & $\begin{array}{l}\text { CLC } \\
\text { code }\end{array}$ & $\begin{array}{l}\text { CLC } \\
\text { colour }\end{array}$ & CLC class name (level 3) & $\begin{array}{c}\text { Type of land cover (CLC } \\
\text { level 1) }\end{array}$ & Appearance on test sites \\
\hline 1. & 112 & & Discontinuous urban fabric & Artificial surfaces & FR, PL, ES, DE, IT, LV \\
\hline 2. & 121 & & Industrial or commercial units & Artificial surfaces & , , DE, IT, \\
\hline 3. & 131 & & Mineral extraction sites & Artificial surfaces & $\mathrm{FR}, \quad, \quad, \mathrm{DE}$ \\
\hline 4. & 132 & & Dump sites & Artificial surfaces & $, \quad, \mathrm{DE}$ \\
\hline 5. & 211 & & Non-irrigated arable land & Agricultural areas & FR, PL, ES, DE, IT, LV \\
\hline 6. & 221 & & Vineyards & Agricultural areas & $\mathrm{FR}, \quad, \mathrm{ES}, \quad, \quad$, \\
\hline 7. & 222 & & Fruit trees and berry plantations & Agricultural areas &,$\quad$, ES, DE, , LV \\
\hline 8. & 223 & & Olive groves & Agricultural areas & $, \quad, \quad$, IT, \\
\hline 9. & 231 & & Pastures & Agricultural areas & FR, PL, , DE, , LV \\
\hline 10. & 242 & & Complex cultivation patterns & Agricultural areas & FR, PL, ES, DE, IT, LV \\
\hline 11. & 243 & & $\begin{array}{l}\text { Land principally occupied by agriculture, } \\
\text { with significant areas of natural vegetation }\end{array}$ & Agricultural areas & FR, PL, ES, , IT, LV \\
\hline 12. & 244 & & Agro-forestry areas & Agricultural areas &,$\quad$, IT, \\
\hline 13. & 311 & & Broad-leaved forest & Forest and semi natural areas & FR, PL, ES, , IT, LV \\
\hline 14. & 312 & & Coniferous forest & Forest and semi natural areas & FR, PL, , DE, , LV \\
\hline 15. & 313 & & Mixed forest & Forest and semi natural areas & FR, PL, ES, DE, \\
\hline 16. & 321 & & Natural grasslands & Forest and semi natural areas & $, \quad, \quad, \quad$, IT, LV \\
\hline 17. & 323 & & Sclerophyllous vegetation & Forest and semi natural areas & , , ES, , IT, \\
\hline 18. & 324 & & Transitional woodland-shrub & Forest and semi natural areas & $\mathrm{FR}, \quad, \mathrm{ES}, \quad, \quad, \mathrm{LV}$ \\
\hline 19. & 331 & & Beaches, dunes, sands & Forest and semi natural areas & $, \quad, \mathrm{ES}$ \\
\hline 20. & 333 & & Sparsely vegetated areas & Forest and semi natural areas & , ES, \\
\hline 21. & 411 & & Inland marshes & Wetlands & FR, , , , , \\
\hline 22. & 412 & & Peat bogs & Wetlands & $, \quad, \quad$, \\
\hline 23. & 511 & & Water courses & Water bodies & FR, , , , \\
\hline 24. & 512 & & Water bodies & Water bodies & $, \mathrm{PL}, \quad, \quad, \quad, \mathrm{LV}$ \\
\hline
\end{tabular}

visible on SATChMo classification, while on CLC maps they are assigned to one class (243). Test site in Germany is similar to Polish test area (10 CLC classes), although has different spatial pattern, which is evident on both types of classification. German test site has the low number of thematic categories ( 6 classes). Among the remaining three test sites Latvia and Spain are characterized by the highest number of natural and semi-natural classes (six, including wetlands and water reservoirs). Spanish test site has also the highest percentage of natural and semi-natural classes $(52 \%)$. Italian test site located on Sardinia is characterized by big differences in spatial pattern of natural and semi-natural classes for both classifications. Natural and semi-natural areas are divided in this region into high number of small polygons located between fields; sometimes they form larger structures, but with the elongated shapes. This pattern is well visible on SATChMo classification, while on CLC classification only large areas of natural and semi-natural areas appear. Considering that test sites in France and Poland represent extremely different areas, as far as homogeneity is concerned, indicators for first two groups will be presented using these study areas. In case of indicators related to natural and semi-natural areas, results will be demonstrated using test sites from Spain, Italy and Poland, as they reveal important differences between both types of classification. 


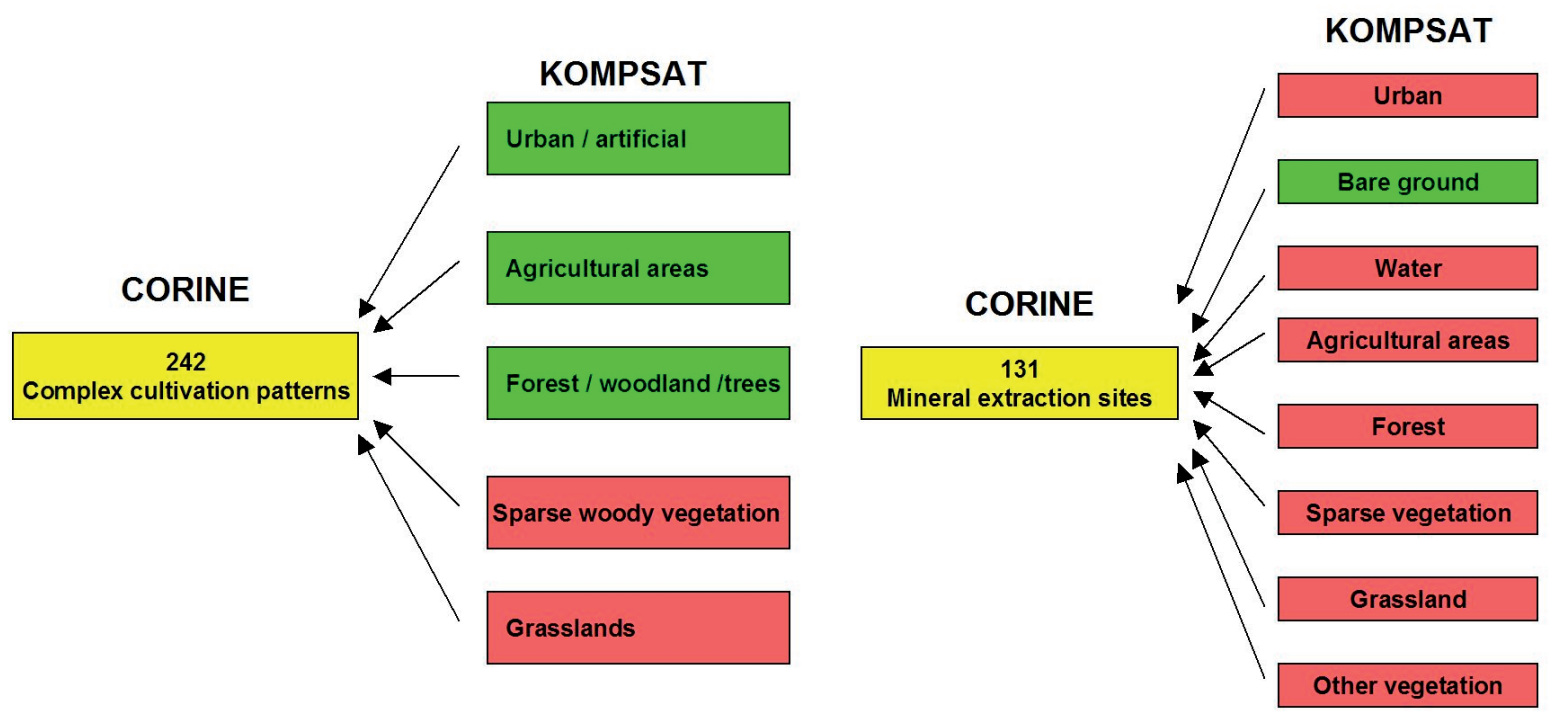

Figure 3a. Example of non-compatibility of SATChMo and CORINE Land Cover classification legends (1)

\section{Materials and methods}

Two land cover maps: CLC 2006 and classification based on VHR Kompsat images were the input materials for calculating all indicators. Classification maps were generated with the use of semi-automatic tool prepared jointly by the Institute of Geodesy and Cartography and Space Research Centre within eCognition environment, in the framework of FP7 Geoland 2 SATChMo project (Lewiński et al., 2010, 2011). Classification legend includes 10 classes (Fig. 2) but two classes (snow and ice, clouds and voids) do not appear on six study areas. Minimum Mapping Unit for these classifications is 0.25 ha. CORINE Land Cover (CLC) maps were used applying CLC 2006 vector data available for the whole Europe at the internet website: http://www.eea.europa.eu/data-andmaps/data/clc-2006-vector-data-version-2. Particular thematic layers were adjusted in size to dimensions of Kompsat scenes. Next, all classes were combined into one vector layer and converted to raster form with $4 \mathrm{~m}$ resolution (the same as for Kompsat images). Minimum mapping unit in case of CLC map is 25 ha (100 times larger than in case of SATChMo classification).

Both classifications differ in spatial resolution, as well as in thematic content. Thematic difference lies not only in number of classes, but also in lack of compatibility of two legends, which results from mixed classes in CLC legend $(242,243)$. Examples of non-compatibility were presented in Figures $3 \mathrm{a}$ and $3 \mathrm{~b}$ using French test site.

On the left side of Fig. 3a one mixed class -242 and all classes from SATChMo legend, which can appear within 242 CLC class, are presented. With green colour those SATChMo classes were marked, which are covered by
CLC definition, while with red colour those not matching that definition. That problem does not refer only to mixed CLC classes, but also to homogeneous ones (right side of the Fig. 3a). For example at French test site within CLC class 131, 8 SATChMo classes appear, while only one SATChMo class - bare ground should be included. The remaining classes do not cover thematically CLC class, and their occurrence is caused by low spatial resolution of CLC map.

The thematic non-compatibility can be also observed in reverse direction (Fig. 3b). One class from SATChMo legend can belong to a few CLC classes. For example at French test site built-up areas in SATChMo classification are covered by 6 CLC classes (agricultural areas by 5 CLC classes). Non-compatibility, as previously, is mainly caused by differences in spatial resolution of land cover maps.

Presented above classifications were the input data for calculating seven landscape indicators, which were next divided into 3 groups. First group includes indicators describing degree of landscape fragmentation at patch level (Patch Density and Edge Density). Second group characterizes landscape differentiation at land cover level (Patch Richness, Simpson Diversity Index). The remaining three indicators (Natural Patch Richness, Percent of Natural Landscape, Mean Natural Patch Area) characterize natural and semi-natural areas, which appear at the test sites. In case of CLC classification all classes with the code $3 \mathrm{xx}$, $4 \mathrm{xx}$ and $5 \mathrm{xx}$ were used for the calculation of indicators describing natural and semi-natural areas. For the SATChMo classification forest woodland trees, sparse woody vegetation, grassland and other vegetation classes were taken into account. Due to the different spatial resolution and incompatibility of legends, the extent of natural and semi-natu- 


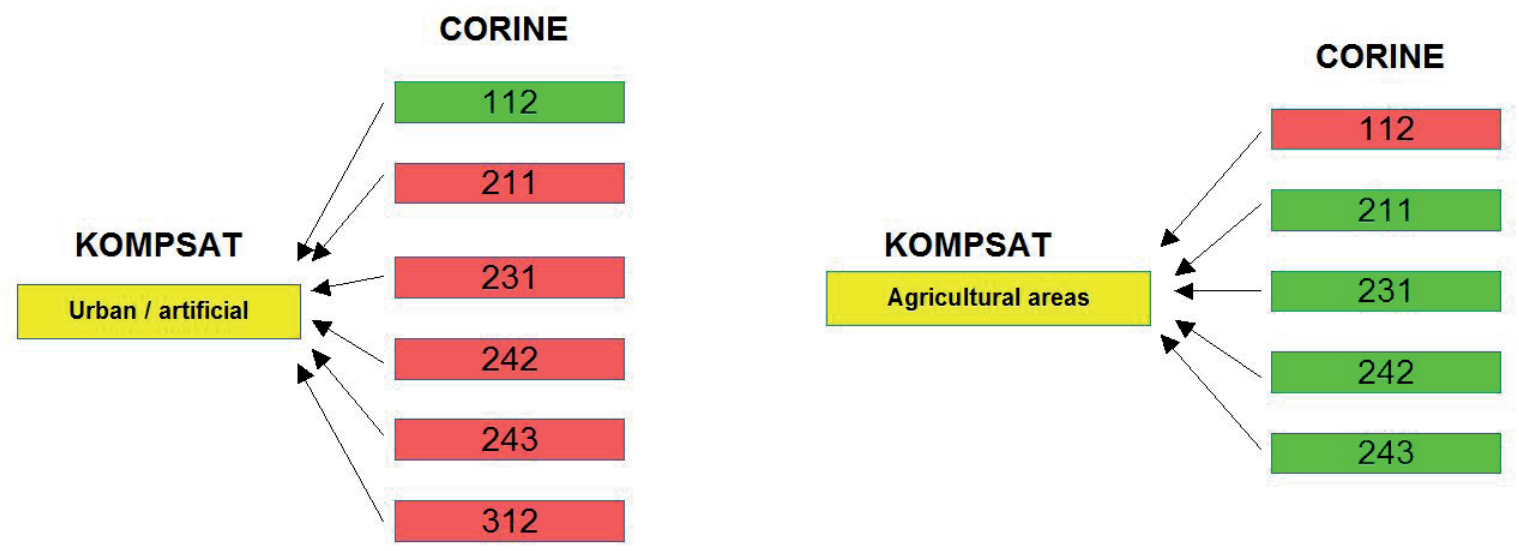

Figure 3b. Example of non-compatibility of SATChMo and CORINE Land Cover classification legends (2)

ral areas is different in both classifications. This problem is discussed later in the paper. First four indicators were taken from the list, which is included at Fragstats software (McGarigal \& Marks 1995). Next three are modifications of Fragstats indicators, based on application of the selected indicators only for natural and semi-natural classes. All indicators were calculated at square grid cells with 100, 200, 500 and $1000 \mathrm{~m}$ cell size, in order to verify usefulness of both legends for landscape analysis, while applying various spatial resolutions. It was assumed that $100 \mathrm{~m}$ cell is the smallest, taking into account spatial and thematic level of detail of both materials and the aim of analysis - landscape fragmentation. The cells larger than $1000 \mathrm{~m}$ were not used due to small size of Kompsat scenes, which would cause the analysis of spatial variability of indicators not possible. However, it should be emphasized that for larger areas, while using CLC maps, application of larger size of grid cell is justified, considering their spatial resolution and thematic content. eCognition and ERDAS IMAGINE software packages were used for calculating indicators. Using these software packages the dedicated tools were prepared, which can generate indicators automatically. Fragstats software was not utilized in the presented work, as it allows for calculating indicators only for the whole scene, without division into basic cells. Short description of the selected indices was given below:

\section{Indicators describing landscape fragmentation}

\section{Patch Density}

This indicator determines number of patches in landscape (basic cell) per landscape area (ha)

$\mathrm{PD}=\mathrm{NP} / \mathrm{A}$, where NP - number of patches in the landscape, A - landscape area (ha).

2. Edge Density
Edge density equals the sum of the lengths (m) of all edge segments in the landscape, divided by the total landscape area $\left(\mathrm{m}^{2}\right)$ :

$\mathrm{ED}=\mathrm{TE} / \mathrm{A}$, where $\mathrm{TE}-$ total edge, $\mathrm{A}-$ landscape area (ha).

Both indicators include complementary information related to landscape fragmentation. High value of Patch Density does not always imply high value of Edge Density. It must be remembered, that results of calculations can be influenced by some artifacts. In case of Patch Density it results from intersecting patch boundaries with cell borders, which in turn causes, that one polygon is divided into several fragments. The problem becomes important in case of large polygons with long, complex boundaries. Artifacts in Edge Density indicator result from the way of its calculating along boundaries of pixels, which causes, that values of indicator can be higher by 1.41 (length of square diagonal divided by length of side). In theory this value can be also lower, but considering $4 \mathrm{~m}$ resolution these cases do not appear. Edge Density indicator is more convenient due to one legend, irrespective of size of cell.

\section{Indicators describing landscape differentiation by land cover types}

3. Patch Richness

Patch Richness equals the number of different patch types present within the landscape boundary:

$\mathrm{PR}=m$, where $m$ - number of patch types (classes) present in the landscape.

Value of this indicator usually increases, while cell size is larger. Minimum value - 1 , maximum value - number of classes existing within the area

4. Simpson Diversity Index 
Simpson Diversity Index equals 1 minus the sum, across all patch types, of the proportional abundance of each patch type squared:

$\mathrm{SIDI}=1-\sum_{i=1}^{m} P_{i}^{2} 1-\sum_{i=1}^{m} P_{i}^{2}$, where $P_{i} P_{i}-$ proportion of the landscape occupied by patch type (class) $i$.

Value of indicator can change from 0 to 1 . Zero value denotes, that only one class appears within the grid cell.

Both indicators deliver somewhat different information. Patch Richness informs only about number of land cover classes within grid cell, while SIDI value also depends on percent contribution of each class within the cell. Owing to its complexity SIDI indicator conveys more information on spatial differentiation than Patch Richness. Unfortunately, this complexity can also cause some difficulties in interpretation. Without information on number of classes in grid cell (Patch Richness) we cannot be sure, if increase of SIDI indicator is caused due to larger number of classes or only due to changes in proportion of classes. At some proportions it can happen, that cells with larger number of classes can have lower values of SIDI indicator.

\section{Indicators describing natural and semi-natural areas}

5. Natural Patch Richness (NPR) - Patch Richness from Fragstats suite, applied solely for natural and semi-natural classes

Natural Patch Richness equals the number of different natural and semi-natural patch types present within the landscape boundary:

$\mathrm{NPR}=m$, where $m-$ number of natural and semi-natural patch types (classes) present in the landscape.

NPR is dimensionless and always greater or equal 0 . When PR equals 0 , the natural and semi-natural classes are not presented within the landscape. When PR equals 1 , the landscape is composed with only one natural or semi-natural class (one natural or semi-natural land cover type).

6. Percentage of Natural Landscape (PNLAND)

This index is the modification of Percent of Landscape Index derived from Fragstats and applied only to natural and semi-natural classes

PNLAND equals the sum of the areas $\left(\mathrm{m}^{2}\right)$ of all natural and semi-natural patches within the landscape, divided by total landscape area $\left(\mathrm{m}^{2}\right)$, multiplied by 100 (to convert to a percentage); in other words, PNLAND equals the percentage the landscape comprised of the natural and semi-natural patch types. Note, total landscape area (A) includes any internal background present.

PNLAND approaches 0 when there is no natural and semi-natural patches in the landscape. PNLAND $=100$ when the entire landscape consists only of natural and semi-natural patch types.

7. Mean Natural Patch Area (MNPA)

Mean Natural Patch Area equals the mean area of natural and semi-natural patch within the landscape
$\mathrm{MNPA}=\operatorname{SQRT}\left(\left(\mathrm{X}_{1}{ }^{2}+\mathrm{X}_{2}{ }^{2}+\mathrm{X}_{3}{ }^{2}+\ldots\right) / \mathrm{N}\right)$, where $\mathrm{X}_{1}, \mathrm{X}_{2}, \mathrm{X}_{3} \ldots$ is the mean patch area of single natural or semi-natural patch type in the landscape; $\mathrm{N}$ is the number of different natural and semi-natural patch types (classes) in the landscape.

$0<\mathrm{MNPA}<\mathrm{A}$, where $\mathrm{A}$ is the total area of the landscape.

MNPA approaches 0 when natural and semi-natural classes do not exist in the landscape. MNPA approaches A when the entire landscape consists only of one natural or semi-natural class. Note, when entire landscape consists of natural and semi-natural classes (more than one), the value of MNPA is less then A. This index is not redundant with Percent of Natural Landscape Index.

All three above mentioned indicators deliver different, complementary information on natural and semi-natural areas. First indicator informs about number of natural classes, while the second on their percent contribution to landscape. Both indicators are related to land cover classes, while third indicator is dependent on mean area of natural classes. It means, that for area totally covered by one natural vegetation it will not reach maximum values, if more than one class will appear within grid cell.

More information about the applied indicators can be found on Fragstats website

http://www.umass.edu/landeco/research/fragstats/fragstats.html and in the literature: (McGarigal \& Marks 1995).

\section{Results and discussion}

All above presented indicators were calculated for four sizes of grid cell (100, 200, 500 and $1000 \mathrm{~m}$ ), for two land cover maps and for six test sites. Additionally, for SATChMo classification indicators were calculated for two dates and maps of changes of indicators were produced. It means, that 504 maps of indicators and their changes were generated on the basis of SATChMo classifications and 168 maps for CLC classifications (in total 672 maps). Only selected examples can be demonstrated in graphical form, although conclusions are drawn from the whole available material. The results of analysis were divided into three groups related to: landscape fragmentation at patch level, differentiation at land cover level and spatial pattern of natural and semi-natural areas.

\section{a. Landscape fragmentation}

Usefulness of SATChMo and CLC classifications for analysis of landscape fragmentation at patch level has been presented using Edge Density indicator as an example. This indicator is much more convenient than Patch Density due to one scale of values, irrespective of size of grid cell. The presented examples (Figs. 4a and 4b) concern France and 
Poland, as these test sites are very different, as far as heterogeneity on patch level is concerned. It can be clearly visible, that in case of indicators based on SATChMo classifications the best results are obtained using the smallest grid cells (100 and $200 \mathrm{~m})$. In these cases one can reach the largest range of values - from 0 to $600 \mathrm{~m}$ per ha. At the same time due to small size of grid cell the best image of spatial differentiation is obtained within the test site, both for heterogeneous French and homogeneous Polish test area. While increasing cell size range of values decreases, as well as spatial differentiation. It results from merging within cell areas characterized by large and small amount of boundaries, as well as from the fact, that areas with high density of boundaries appear at relatively small parts of landscape. While increasing size of cell great potential of SATChMo classification, resulting from very high spatial resolution, is being lost. In case of indicators based on CLC classification it can be clearly visible, that they are less useful for analysis of landscape fragmentation at patch level; the obtained results are much reliable than those based on SATChMo classification, irrespective of cell size - much smaller range of indicator's variability is observed. In case of 100 and $200 \mathrm{~m}$ cells variations of indicator reflect only boundaries of polygons, which are much larger than cell size. While increasing size of grid cell dynamics of variability decreases, in particular for homogeneous test site in Poland, where only one cell reaches value greater than $50 \mathrm{~m}$ per ha. Moreover, it should be mentioned, that values of indicators based on CLC classification are far from reality due to high generalization. Therefore in such a local scale, which is presented in this work, they do not reflect real degree of landscape fragmentation.

Conclusions, which were presented above also concern the remaining test sites and the second applied indicator Patch Density; the results are very similar. Range of values is much higher for SATChMo classification than for CORINE Land Cover. In both cases values of indicators and their spatial variability decrease while increasing size of grid cell. Differences between both indicators result from place of local maximum of values within scene; it means that long boundaries are not always related to the large number of polygons.

\section{Landscape pattern at land cover level}

In case of indicators characterizing landscape pattern it is not important, how many polygons are within grid cell number of different land cover classes is the base for their calculation. In the presented work landscape pattern was described by two indicators: Patch Richness and Simpson Diversity Index (SIDI). As they deliver somewhat different information examples of both indicators were presented. Contrary to previous group of indices Patch Richness and SIDI values and their spatial variability increase, while increasing size of grid cell. It is quite obvious, as while increasing cell size probability of appearing next type of land cover increases. Therefore, despite high spatial resolution of SATChMo classification, the best results for both indicators (in particular Patch Richness) are obtained for 500 and $1000 \mathrm{~m}$ cells. It was assumed at this work, that the smallest cell size, in which indicator reaches its maximum value, is the best for analysis of landscape pattern. In case of Patch Richness maximum value equals to number of possible land cover classes - for France and Poland 8 classes. For heterogeneous French test site this value is reached for $500 \mathrm{~m}$ cell (Fig. 5a), while for homogeneous Polish test site for $1000 \mathrm{~m}$ cell (Fig. 5b). One of these values is applied for the remaining test sites. In case of Patch Richness indicator based on CLC map grids with 100 and $200 \mathrm{~m}$ cells seem to be useless (Fig. 5a and 5b). In case of 500 and $1000 \mathrm{~m}$ cells indicator values are usually lower than those based on SATChMo classification, in spite of higher number of thematic classes in CLC map. It results from large Minimum Mapping Unit of CLC map (25 ha), corresponding to one-fourth of area of $1000 \mathrm{~m}$ cell. For such large delineations only sporadically 5 or 6 land cover classes can appear within grid cell. Occasionally it happens, that PR value based on CORINE Land Cover is higher than that based on SATChMo classification.

In case of SIDI indicator (Fig.6a and 6b) situation is somewhat different. Quite high range of values based on SATChMo classification appears already for 100 and 200 $\mathrm{m}$ cells, while for CLC classification for 500 and $1000 \mathrm{~m}$ cells. The largest spatial differentiation of this indicator based on SATChMo classification is observed at $500 \mathrm{~m}$ cell for heterogeneous French test site and 500-1000 m cell for homogeneous Polish test site. In case of SIDI indicator there are distinct differences in spatial distribution of values between CLC and SATChMo, which is the result of thematic differences of both classifications. There are also many areas, where SIDI value is higher for CLC than for SATChMo. It can result from higher number of thematic classes, but it's not the only reason. It should be remembered, that in case of SIDI value of this indicator is influenced not only by number of classes, but also by percent contribution of each class. So, in some situations value is high despite smaller number of classes. It occurs, when for small number of classes large differences in percent contribution of each class appear. It can explain situation, where for some grid cells SIDI value based on CLC is higher than that based on SATChMo.

Analyzing spatial distribution of SIDI indicator based on both types of input data one can get impression, that in case of 500 and $1000 \mathrm{~m}$ cells the results are comparable. It is not fully justified, as not only distribution of values is important, but also their matching with real world. In case of CLC there is great discrepancy for mixed classes -242 and 243, being in practice mixture of various land 


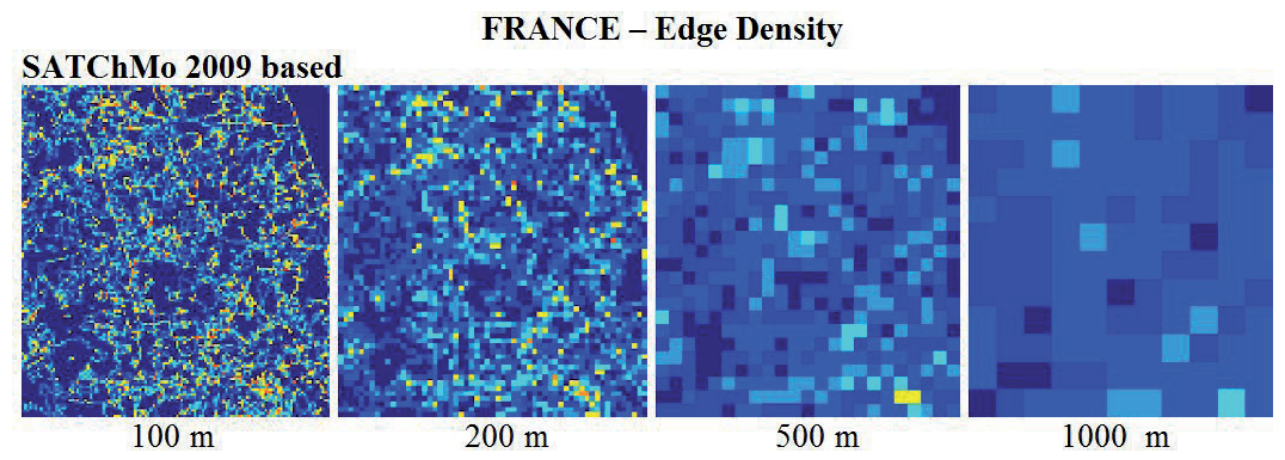

\section{CORINE 2006 based}

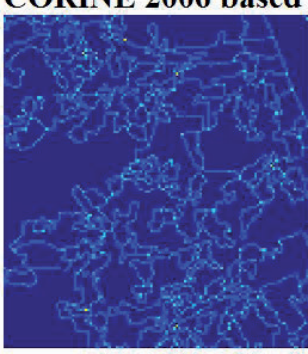

$100 \mathrm{~m}$

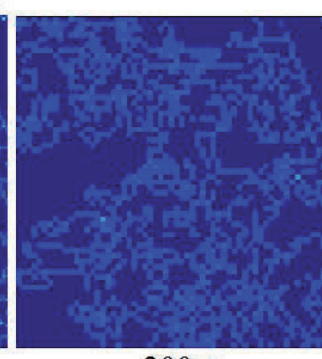

$200 \mathrm{~m}$

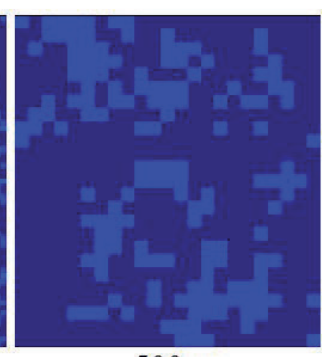

$500 \mathrm{~m}$

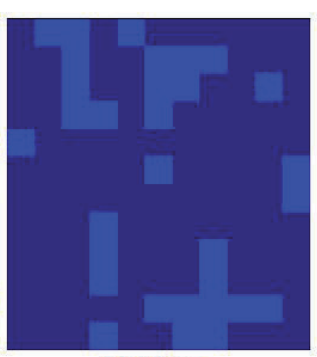

$1000 \mathrm{~m}$

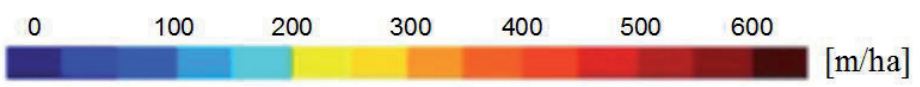

Figure 4a. Edge Density indicator - French test site

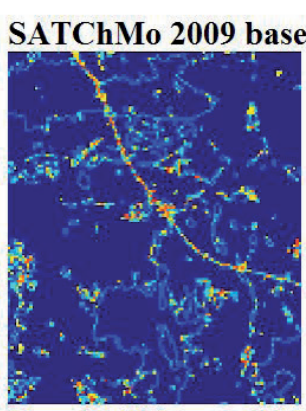

$100 \mathrm{~m}$

POLAND - Edge Density

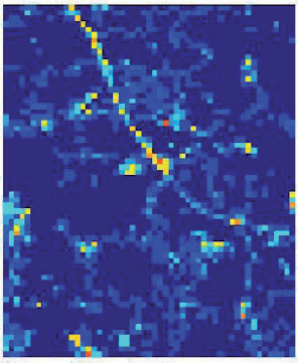

$200 \mathrm{~m}$

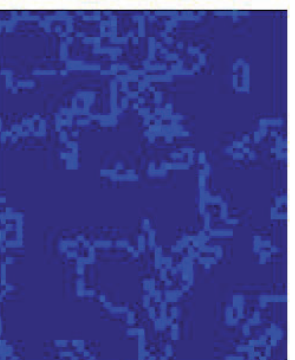

$200 \mathrm{~m}$

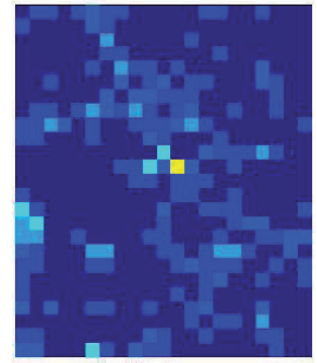

$500 \mathrm{~m}$

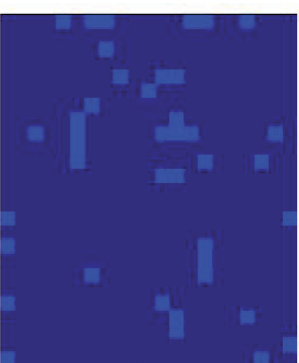

$500 \mathrm{~m}$

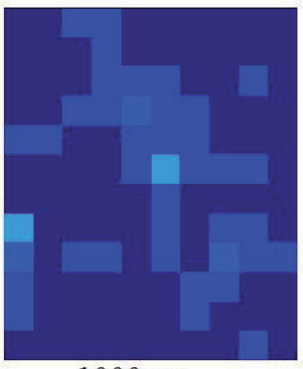

$1000 \mathrm{~m}$

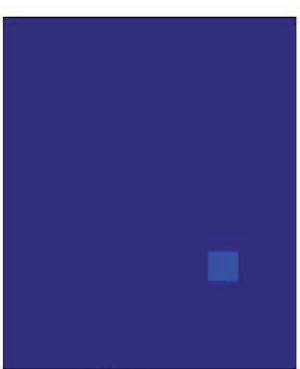

$1000 \mathrm{~m}$

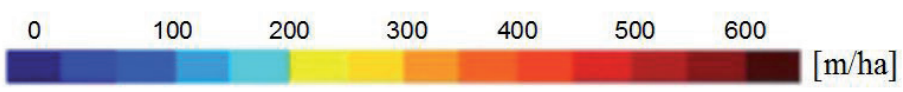

Figure $4 b$. Edge Density indicator - Polish test site 


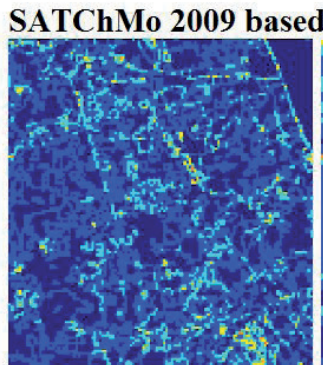

$100 \mathrm{~m}$

FRANCE - Patch Richness

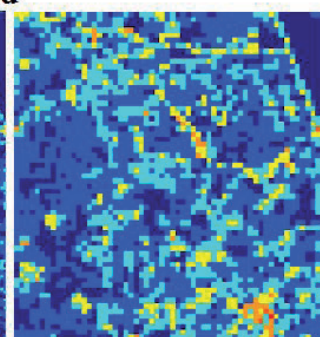

$200 \mathrm{~m}$

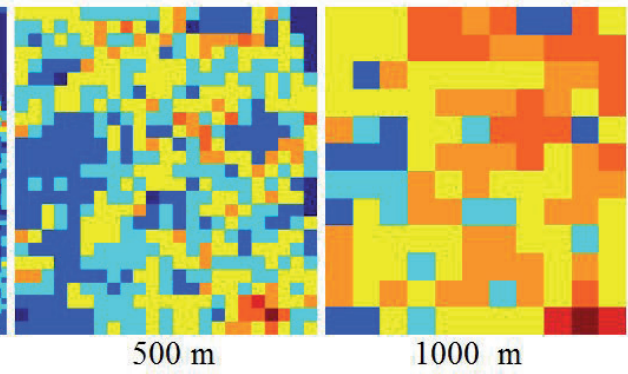

CORINE 2006 based

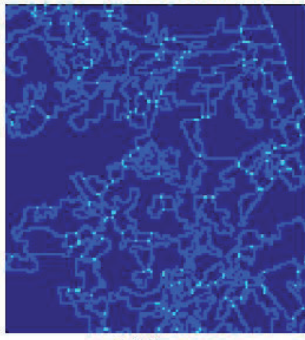

$100 \mathrm{~m}$

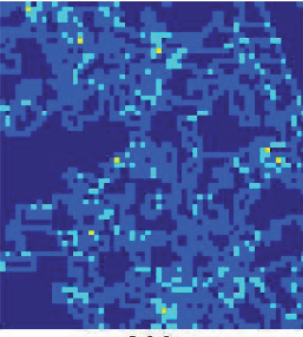

$200 \mathrm{~m}$

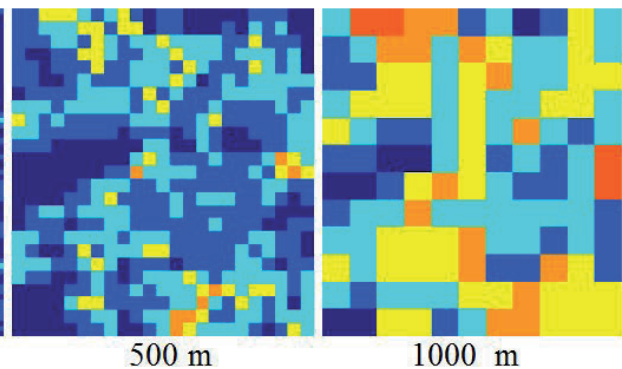

$\begin{array}{llllllll}1 & 2 & 3 & 4 & 5 & 6 & 7 & 8 \\ \end{array}$

Figure 5a. Patch Richness Index - French test site

\section{POLAND - Patch Richness}

SATChMo 2009 based

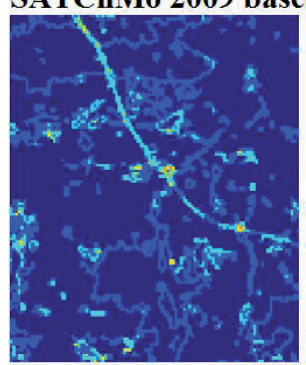

$100 \mathrm{~m}$

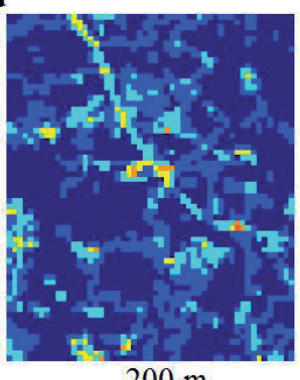

$200 \mathrm{~m}$

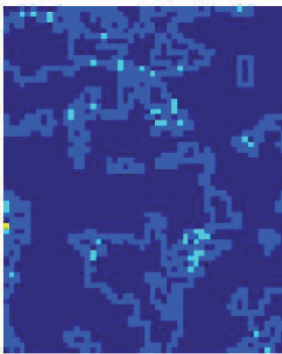

$200 \mathrm{~m}$

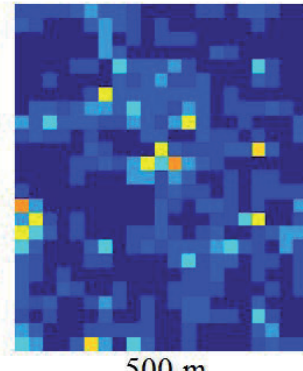

$500 \mathrm{~m}$

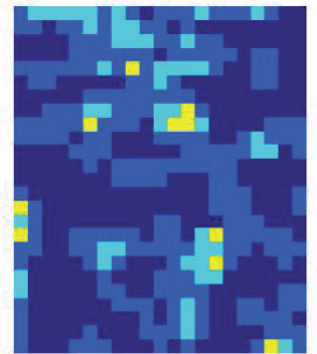

$500 \mathrm{~m}$
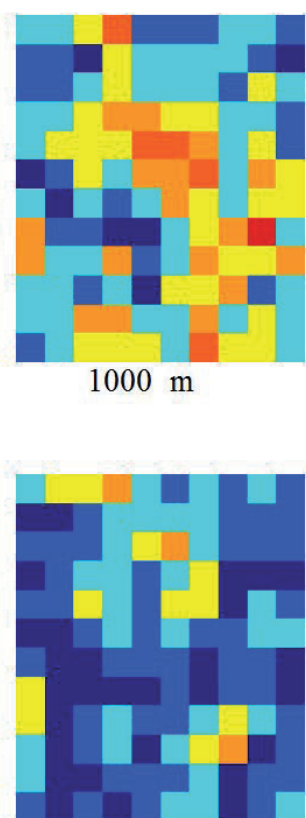

$1000 \mathrm{~m}$

$100 \mathrm{~m}$

$\begin{array}{lll}6 & 7 & 8\end{array}$

Figure 5b. Patch Richness Index - Polish test site 


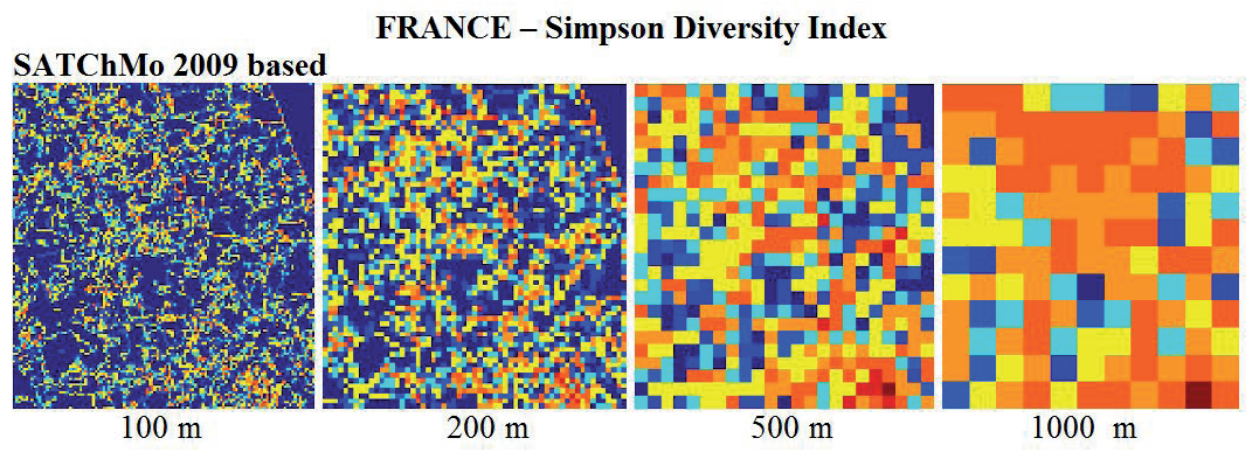

CORINE 2006 based

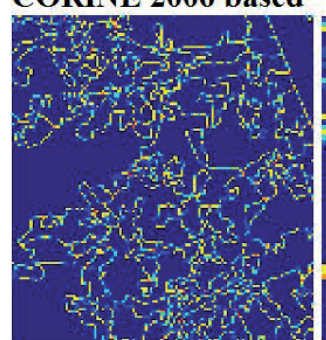

$100 \mathrm{~m}$

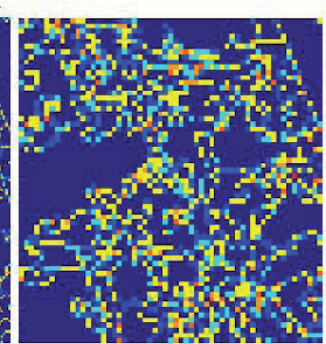

$200 \mathrm{~m}$

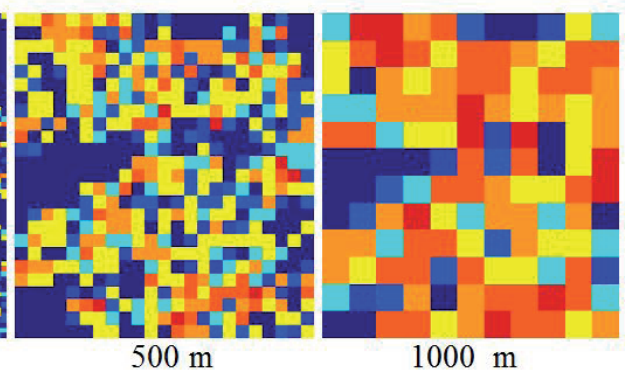
[dimensionless]

Figure 6a. Simpson Diversity Index - French test site

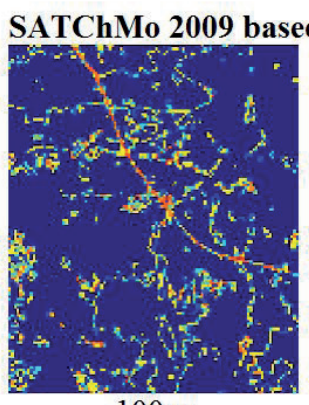

$100 \mathrm{~m}$

\section{POLAND - Simpson Diversity Index}

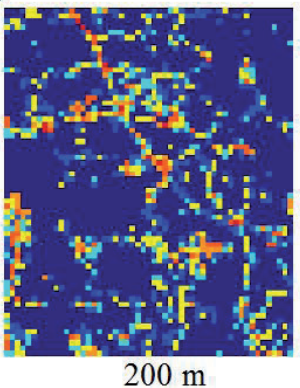

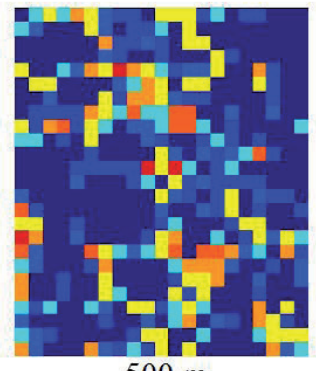

$500 \mathrm{~m}$

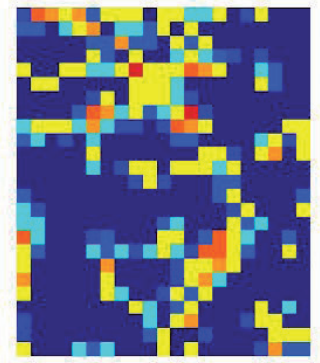

$500 \mathrm{~m}$

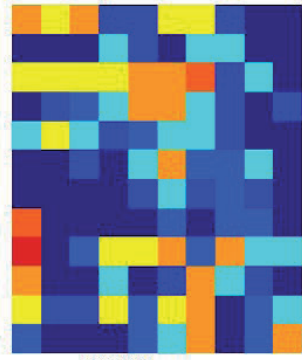

$1000 \mathrm{~m}$

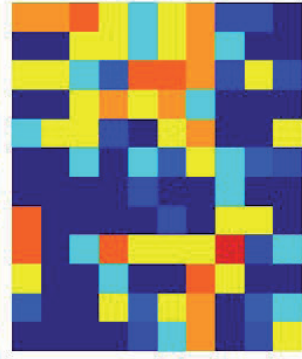

$1000 \mathrm{~m}$

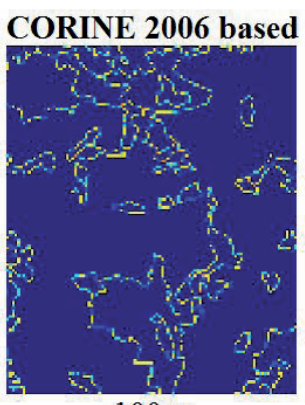

$100 \mathrm{~m}$

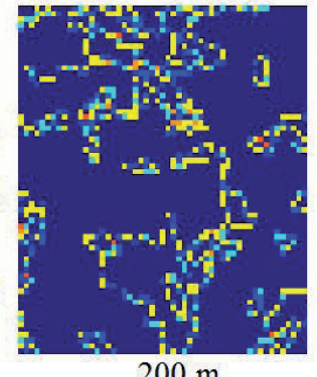

$200 \mathrm{~m}$
$0.8 \quad 1$

[dimensionless]

Figure 6b. Simpson Diversity Index - Polish test site 
cover types. They are classified as one class, despite being highly fragmented due to appearance of small polygons representing different classes, which are below MMU - 25 ha. It results in small values of landscape fragmentation indicator for areas, where fragmentation is de facto the highest. There is one conclusion - for areas, where large areas of mixed classes appear, CLC map is not suitable for analyzing landscape fragmentation neither at land cover level nor at patch level. Such a situation exists for Polish test site (242 and 243 classes) and for Italian test site (244 class). It means, that for these test sites results based on SATChMo classifications are more reliable. It can happen, that better results will be obtained while using CLC map, for instance when spatial variability of land cover classes is not high ( 25 ha is not a limitation) and better thematic content of CLC map allows for higher number of classes than in case of SATChMo classification. Such situation exists on test sites used in the presented work, for instance compact coniferous and deciduous forest areas, which are represented in SATChMo legend as one class.

The discussion leads to conclusion, that while choosing type of input data for analysis of spatial pattern of landscape at land cover level character of the study area must be taken into account. The detailed analysis of six test sites revealed, that at these regions those areas much more frequently appear, where better results are obtained on the basis of SATChMo classifications.

\section{Indicators describing natural and semi-natural classes}

Three indicators have been selected for analysis of fragmentation and spatial pattern of natural and semi-natural classes: Natural Patch Richness, Percent of Natural Landscape and Mean Area of Natural Polygons. Great differences in spatial distribution of indicators based on CLC and on SATChMo can be observed, due to differences in spatial resolution and thematic content. Analysis of these indicators for six test sites reveals, that they are complementary (not correlated), as somewhat different conclusions can be drawn for each indicator.

Natural Patch Richness (NPR) indicator was presented on the basis of Spanish test site, as it is characterized by the highest contribution of natural vegetation (over 52 $\%$ ) and by the highest number of natural and semi-natural classes in CORINE legend ( 6 classes). Also French test site was used due to heterogeneity of this area. French test site includes 4 natural classes in both classifications. Spatial distribution of this indicator for all cell sizes is presented in Figure 7a (for Spain) and Figure 7b (for France). As NPR is in principle Patch Richness, but applied to natural areas, conclusions concerning application of these indicators for various classifications and grid cells are very similar.

Different spatial distribution of indicator based on both classifications, resulting from various thematic content and spatial resolution, can be even better visible than in case of Patch Richness. For both classifications 500 and $1000 \mathrm{~m}$ cells seem to be the best for analysis. It can be observed, that for Spanish test site, in spite of high number of natural classes in CLC legend, NPR does not reach maximum potential value for this area (6), even for 1000 m cells. In some places values based on CLC map are slightly higher, but reverse situation also often exists.

On the other test sites NPR values based on SATChMo classification are often higher, reaching faster maximum values. For example, for French and Polish test sites maximum NPR value can be 4 . In case of heterogeneous French test site this value based on SATChMo is reached using $500 \mathrm{~m}$ cells, while based on CLC map when using 1000m cells. In case of homogeneous Polish test site SATChMo based NPR reaches maximum value for $1000 \mathrm{~m}$ cells, whereas using this cell and CLC maps maximum value is 2. Differences appear not only in maximum values, but also in frequency of occurrence of higher values. It can be observed, that higher values more often appear, while using SATChMo based indicator; it applies to all test sites. This situation can be explained by much lower spatial resolution of CLC map, which does not allow high number of natural classes to appear. Wider thematic content of CLC map would be probably usable while using larger grid cells (over $1000 \mathrm{~m}$ ), but large cell would cause, that information on spatial distribution of natural classes and their fragmentation would be less readable.

The next indicators - Percent of Natural Landscape and Mean Natural Patch Area - considering formula, can be applied at both maps for all sizes of grid cells, from 100 to $1000 \mathrm{~m}$ (the selected examples for $100 \mathrm{~m}$ cell are presented further). But due to better spatial resolution of SATChMo classification it is more predestinated to deliver more reliable information on appearance of natural classes. However, it must be remembered, that for small grid cells patches of natural classes are often larger than cells, which implies appearance of artifacts. Application of small grid cells does not allow for presentation of full variability of natural classes within analyzed areas. So it should be concluded, that these indicators are better while using larger grid cells. As mean patch area for SATChMo classification is much smaller than for CLC map, in this case that indicator can be applied for smaller grid cells.

In case of natural and semi-natural areas it must be also emphasized that differences in their appearance on both classifications results not only from differences in spatial resolution, but also due to the fact, that in CLC legend so-called mixed classes exist. Class 243 - land principally occupied by agriculture, with significant areas of natural vegetation and class 244 - agro-forestry by definition can include natural areas, although at CLC level 1 belong to agricultural land. However, such an approach leads to under-estimating natural vegetation at some regions. But, 


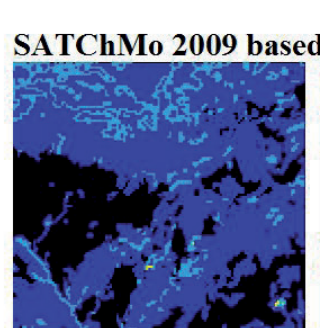

$100 \mathrm{~m}$

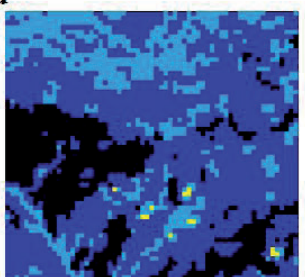

$200 \mathrm{~m}$

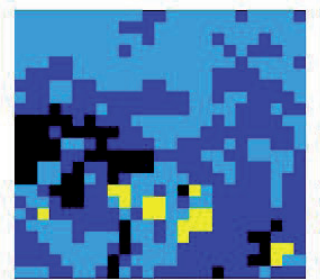

$500 \mathrm{~m}$

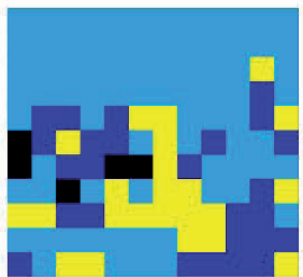

$1000 \mathrm{~m}$

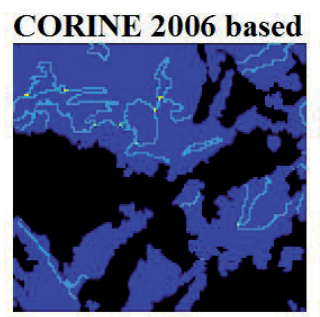

$100 \mathrm{~m}$

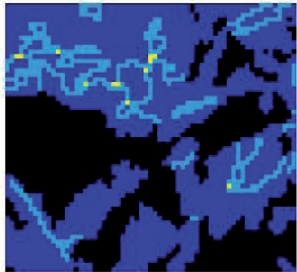

$200 \mathrm{~m}$

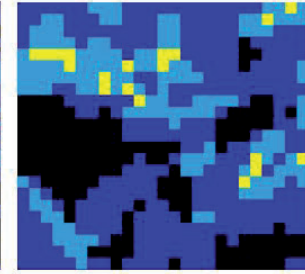

$500 \mathrm{~m}$

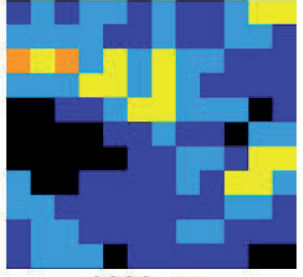

$1000 \mathrm{~m}$

$\begin{array}{llll}0 & 1 & 2 & 3\end{array}$ [Number of natural classes per grid cell]

Figure 7a. Natural Patch Richness indicator for Spanish test site. Upper part - based on SATChMo classification 2009, lower part - based on CLC map 2006

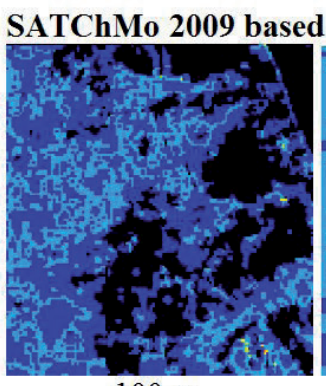

$100 \mathrm{~m}$

FRANCE - Natural Patch Richness

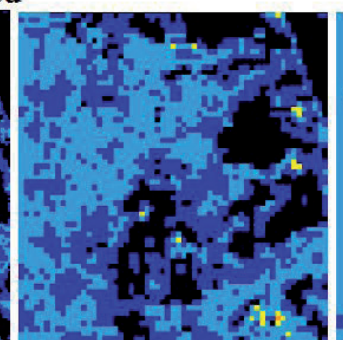

$200 \mathrm{~m}$

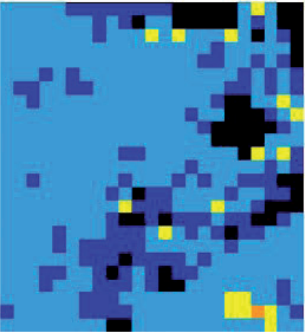

$500 \mathrm{~m}$

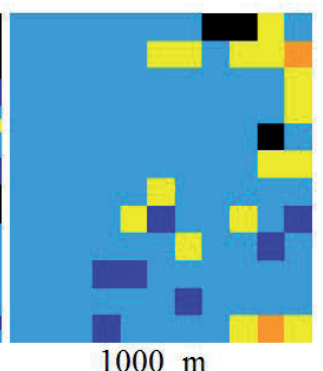

$1000 \mathrm{~m}$

\section{CORINE 2006 based}

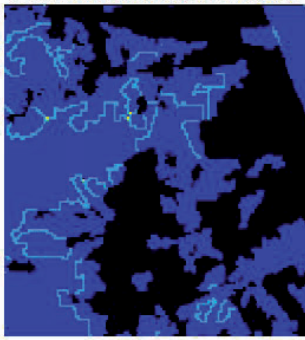

$100 \mathrm{~m}$

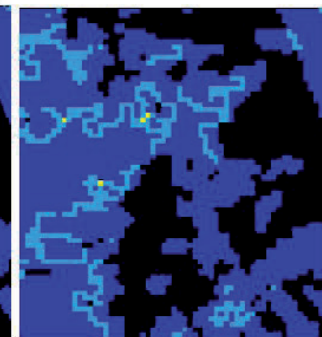

$200 \mathrm{~m}$

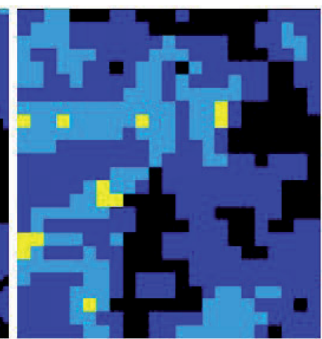

$500 \mathrm{~m}$

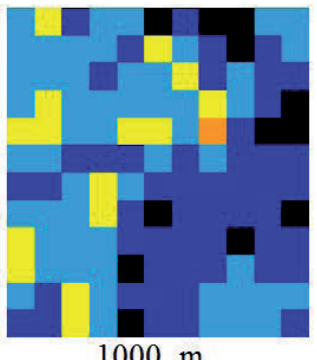

$1000 \mathrm{~m}$

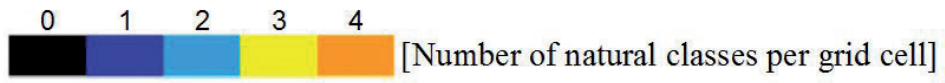

Figure 7b. Natural Patch Richness indicator for French test site. Upper part - based on SATChMo classification 2009, lower part - based on CLC map 2006 
POLAND - Percent of Natural Landscape

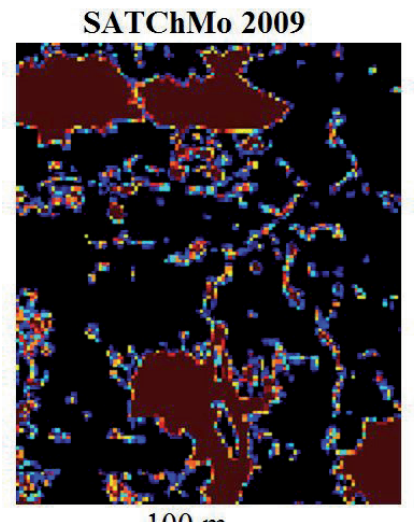

$100 \mathrm{~m}$

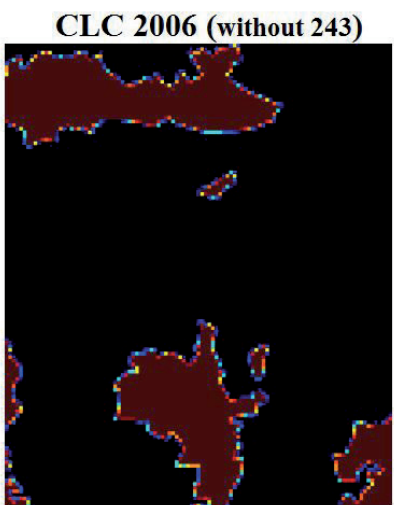

$100 \mathrm{~m}$

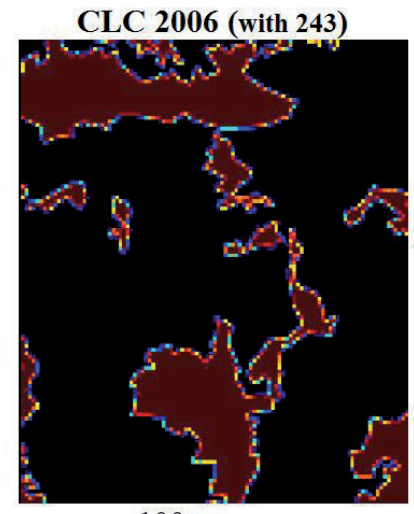

$100 \mathrm{~m}$

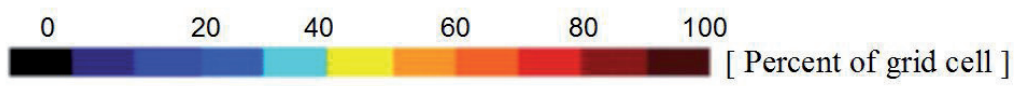

Figure 8. Percent of Natural Landscape (PNLAND) for Polish test site using 100m cell. From left to right: SATChMo 2009 based indicator, CLC 2006 based indicator with inclusion of class 243 to agricultural land, CLC 2006 based indicator with inclusion of class 243 to natural and semi-natural areas

if mixed classes would be included into semi-natural areas, it could cause their high over-estimation at some regions. In figure 8 percent contribution of natural classes on Polish test site is presented, using PNLAND indicator for SATChMo classification, CLC map with class 243 and without it. It can be clearly visible, that for areas, where class 243 exists, PNLAND indicator is higher or lower in relation to SATChMo classification, depending on including (or not) this class to natural and semi-natural areas. It's worth mentioning, that even in case of incorporating class 243 into analysis of natural areas contribution of this class in CLC map is under-estimated, as many small patches are included to agricultural land. It can be well visible in the statistics of natural areas for the whole scene. In case of Polish test site area of natural areas from CLC map is $18.3 \%$ (without class 243) and 22.9\% (with class 243), while within SATChMo classification natural areas cover $23.2 \%$.

The above example proves, that irrespective of applied size of grid cell SATChMo classification is much better for analysis of natural areas, despite higher number of thematic classes in CLC map. It results from construction of CLC legend, which in practice does not allow for precise delineation of natural areas, due to existing mixed classes $(243,244)$, which by definition include both agricultural and natural areas. However, it should be mentioned, that small number of thematic classes within SATChMo classification does not enable to fully exploit potential of high spatial resolution and not always reflects properly variability of natural classes.
Differences in spatial distribution of natural and semi-natural classes on both classifications are even better visible using Italian test site from Sardinia. They result from high fragmentation of natural classes in this region, differences in spatial resolution and different interpretation of land cover types on both maps. The last factor is clearly visible at southeastern part of the scene (Fig. 9 a and b). That part was classified on CLC map as natural grasslands (class 321 - light green), while on SATChMo map as agricultural land (yellow). Differences can be caused by different classification of meadows (natural on CLC map, anthropogenic on SATChMo map) or by erroneous assignment of agricultural land to natural grassland on CLC map. Obviously, these differences in classification have impact on spatial distribution of indicators. But differences in indicator's values do not result only from differences in interpretation approach of input data. There are large areas within the test site, where mosaic of crops and natural vegetation exists, mainly composed of very small forests and woodlands. The detailed spatial distribution of these classes was very well rendered on SATChMo classification. As CLC maps do not allow to delineate such small areas, partly they were classified as agro-forestry (244) and assigned to agricultural land or to natural areas (forests or natural grasslands). It causes obviously great differences in indicator's values, characterizing natural areas. When class 244 appears on CLC map, indicators based on this map reveal lack of natural vegetation, while those based on SATChMo classification demonstrate its high contribution and at the same time high fragmentation. (Fig. 9 c, d, e, 


\section{ITALY}

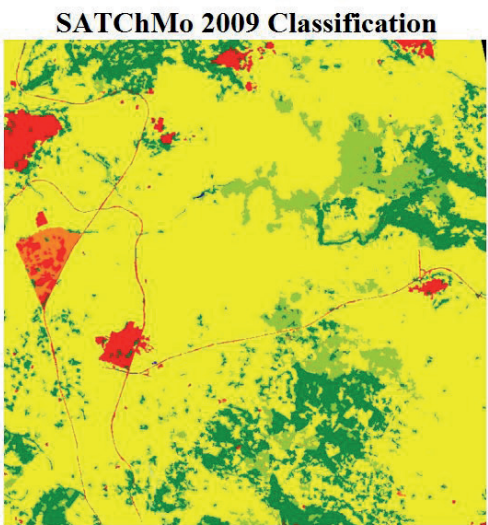

(a)

\section{SATChMo 2009}

Percent of Natural Landscape

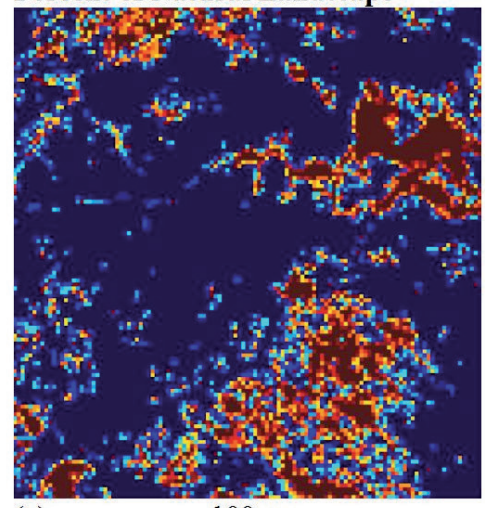

(c)

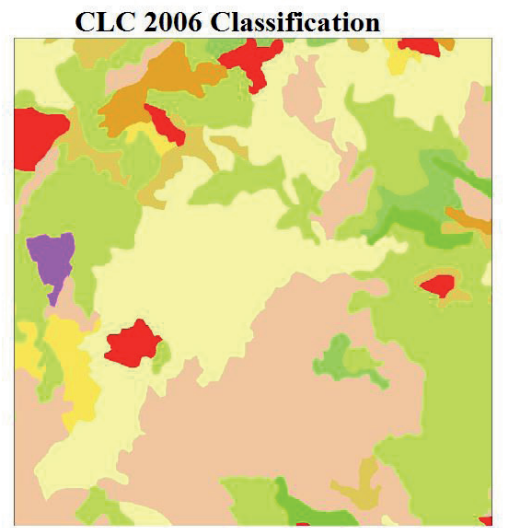

(b)

CLC 2006

Percent of Natural Landscape

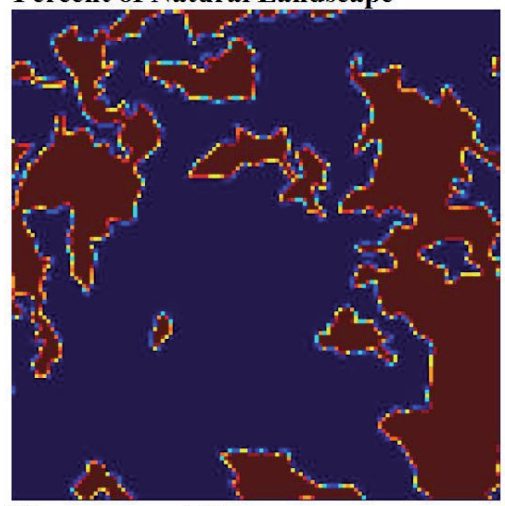

(d)

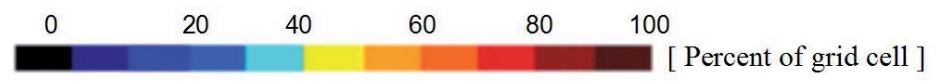

SATChMo 2009

Mean Natural Patch Area

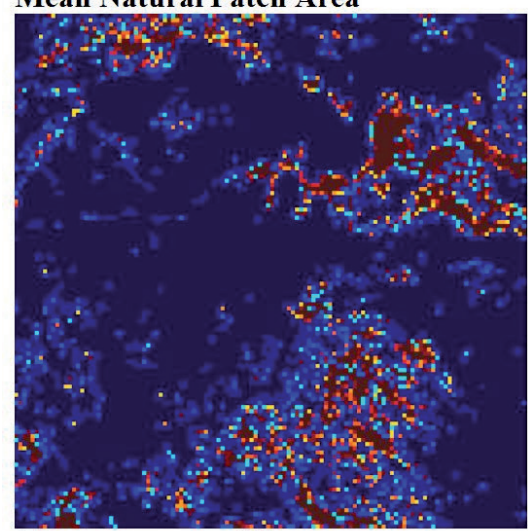

(e)
CLC 2006

Mean Natural Patch Area

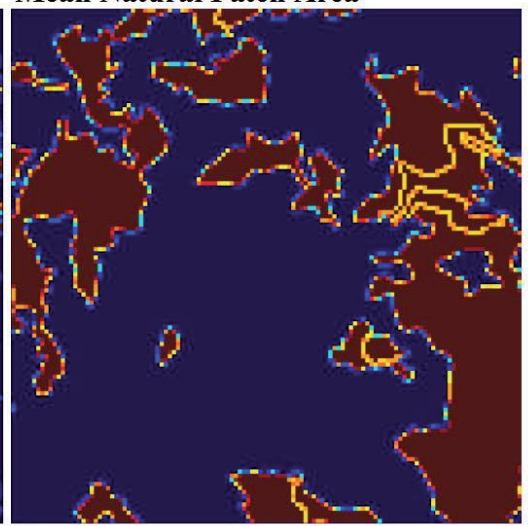

(f)

$100 \mathrm{~m}$

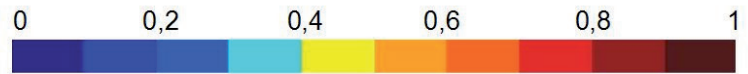

[ $\mathrm{Ha}$ ]

Figure 9. Percent of Natural Landscape (PNLAND) and Mean Natural Patch Area (MNPA) for Italian test site, accompanied by CLC and SATChMo classifications 
f). For areas classified on CLC maps as natural vegetation indicators show large compact natural areas, while those based on SATChMo reveal their real fragmentation. These differences appear irrespective of the used size of grid cell and they are observable for both indices - PNLAND and MNPA. Moreover, MNPA indicates very high fragmentation of the area at patch level, higher than PNLAND at land cover level. It is reflected in many places by very low MNPA indicator value (small mean patch area), while observing relatively high percent of natural vegetation in grid cell. Italian example clearly indicates, that CLC map is not suitable for analyzing spatial distribution of natural areas. Information on appearance of natural areas is not precise, but also due to high generalization presentation of fragmentation is not correct. The most serious problem lies in lower compatibility of indicator's values with real situation (not in lower spatial variability of indicators).

\section{Conclusions}

Comparative analysis conducted at the presented study reveals clearly great differences in information about fragmentation and spatial pattern of landscape, obtained with the use of indicators based on SATChMo classification and on CORINE Land Cover map. These differences are important at any level of detail. In case of landscape fragmentation at patch level SATChMo classifications are superior to CLC map, irrespective of the assumed size of grid cell. In case of analysis at land cover type level SATChMo classification give better results, although sometimes CLC map can be superior. High generalization and appearance of mixed classes in CLC legend are the main shortcomings of this map, although its advantage lies in high number of thematic classes. SATChMo classification, due to very high spatial resolution, gives good results, matched with real situation, especially at the analysis of landscape fragmentation. Its potential is not fully used due to limited number of thematic classes. This factor is especially important, while analyzing landscape pattern at land cover type level, as well as studying natural and semi-natural areas. It also cannot be neglected at analysis of landscape fragmentation at patch level, as higher number of thematic classes involves larger amount of polygons. Undoubtedly, the best input material for analyzing landscape should consist of high spatial resolution data (SATChMo type) with high thematic content (CLC legend), but not using mixed classes existing in CORINE legend. These conditions are not impossible to fulfill, as input satellite data for CORINE map (SPOT and IRS) allow for higher spatial resolution. At the same time Kompsat images - base for SATChMo classifications - enable to obtain much more precise thematic information on land cover types.

\section{References}

Baker W. L., \& Cai Y., 1992, The r le programs for multiscale analysis of landscape structure using the GRASS geographical information system, Landscape Ecology 7: 291-302.

Gardner R. H., R. V., O’Neill R.V. \& Turner M. G., 1993, Ecological implications of landscape fragmentation, Pages 208-226, [in:] S. T. A. Pickett \& M. G. McDonnell (eds.) Humans as components of ecosystems: subtle human effects and ecology of population areas, Springer-Verlag, New York.

http://www.eea.europa.eu/data-and-maps/data/clc-2006vector-data-version-2.

http://www.umass.edu/landeco/research/fragstats/fragstats. html.

Gimona A., Messager P., Occhi M., 2009, CORINE-based landscape indices weakly correlate with plant species richness in a northern European landscape transect, Landscape Ecology (2009) 24: 53-64.

Gulinck H., Múgica M., Vicente de Lucio J., Atauri J.A., 2001, A framework for comparative landscape analysis and evaluation based on land cover data, with an application in the Madrid region (Spain), Landscape and Urban Planning 55: 257-270.

Johnson A. R., Wiens J. A., Milne B. T. \& Crist T. O., 1992, Animal movements and population dynamics in heterogeneous landscapes, Landscape Ecology 7: 63-75.

Lewiński S., Bochenek Z. \& Turlej K., 2010, Application of object-oriented method for classification of VHR satellite images using rule-based approach, Geoinformation Issues 2 (1) 19-26.

Lewiński S., Bochenek Z. \& Turlej K., 2011, Object-oriented method for land cover mapping using VHR satellite images based on decision-tree approach and texture information, 4th EARSeL SIG Workshop on Remote Sensing of Land Use \& Land Cover.

McGarigal K. \& Marks B. J., 1995, FRAGSTATS: spatial pattern analysis program for quantifying landscape structure, Gen. Tech. Report PNW-GTR-351, USDA Forest Service, Pacific Northwest Research Station, Portland, OR.

O’Neill R. V., Krummel J. R., Gardner R. H., Sugihara G., Jackson B., DeAngelis D. L., Milne B. T, Turner M. G., Zygmunt B., Christensen S. W., Dale V. H, \& Graham R. L., 1988, Indices of landscape pattern, Landscape Ecology 1: 153-162.

Schmit C., Rounsevell M. D. A., La Jeunesse L., 2006, The limitations of spatial land use data in environmental analysis, Environmental Science \& Policy 9: 174-188.

Smith G., Ziółkowski D., Kotarba A., Turlej K., Bochenek Z., Lewiński S. \& Dąbrowska-Zielińska K., 2012, Indicators of environmental diversity derived from generic 
land cover products based on VHR satellite images, Technical Report.

Tormos T., Kosuth P., Durrieu S., Villeneuve B., Wasson J. G, 2011, Improving the quantification of land cover pressure on stream ecological status at the riparian scale using High Spatial Resolution Imagery, Physics and Chemistry of the Earth 36: 549-559.

Turner M. G., 1990, Spatial and temporal analysis of landscape patterns, Landscape Ecology 4: 21-30.

Turner M. G., \&. Gardner R. H, (eds.), 1991, Quantitative methods in landscape ecology. Springer-Verlag, New York.
Uuemaa E., Juri Roosaare J., Ulo Mander U., 2005, Scale dependence of landscape metrics and their indicatory, value for nutrient and organic matter losses from catchments, Ecological Indicators 5: 350-369.

With K. A., 1999, Is landscape connectivity necessary and sufficient for wildlife management?, [in:] J. A. Rochelle, L. A. Lehmann \& J. Wisniewski (eds.) Forest fragmentation: wildlife and management implications, Brill, The Netherlands, 97-115.

Wu J., Shen W., Sun W., Tueller P.T., 2002. Empirical patterns of the effects of changing scale on landscape metrics. Landscape Ecology 17 (8): 761-782. 